\title{
LOS CLAROSCUROS DE LA ETNICIDAD. EL CULTURALISMO EVALUADO DESDE LA ÓPTICA DE LA COHESIÓN SOCIAL Y LA CIUDADANÍA
}

\author{
Joan J. Pujadas \\ Docente Departament d'Antropologia, Filosofia i Treball Social (Facultat de Lletres). \\ Universitat Rovira i Virgili, España \\ E-mail: joanjosep.pujadas@urv.cat
}

\section{Resumen}

El siguiente texto profundiza en los conceptos de lo étnico y grupo étnico desde el contexto de las ciencias sociales, se plasma desde una antropología urbana las representaciones de lo étnico y lo cultural en las sociedades de mediados del siglo XX. La investigación elabora un balance historiográfico sobre el debate de lo étnico a partir del discurso que se generó en las últimas cuatro décadas y cuáles fueron sus efectos en el campo socio político, económico y cultural; logra diferenciar entre los rasgos culturales discretos que caracterizan a los grupos sociales de imaginarios colectivo que están representados en prácticas que aseguran la permanencia en grupos sociales y políticos. Con la intención de cristalizar el debate se hace algunos acercamientos desde la etnografía para manifestar los retos que deben asumir las sociedades frente a la discriminación y el etnocentrismo para así llegar a la cohesión social.

Palabras Clave: Étnico, Grupos étnicos, Etnografía, Grupos sociales, cohesión social, discriminación.

\begin{abstract}
The following work emphasizes the ethnic and ethnic group concept from social science context, it displays from an urban anthropology the representations of what is ethnic and cultural in societies from half of the twentieth century. This research develops a historical balance about the ethnic debate from the discussion that were generated in the last four decades and which were the effects in the social, political, economic and cultural field. It is able to differentiate between discreet cultural features that are characteristic of social groups from the imaginary collectivity that are represented in the practices that assure the permanence of social and political groups. With the intention of crystallize the debate, some approaches are made from the ethnography to express the challenges that must be assumed by society towards discrimination and ethnocentrisms, in order to obtain social cohesion.
\end{abstract}

Key words: Ethnic, ethnic groups, social groups, social cohesion, discrimination.

\section{Résumé}

Ce texte explore les concepts d'ethnicité et de groupe ethnique à partir du contexte des sciences sociales, anthropologie urbaine du plasma à partir d'une représentation des sociétés ethniques et culturelles de la moitié du XXe siècle. La recherche développe un bilan historiographique sur la discussion de l'ethnicité dans le discours qui a été généré au cours des quatre dernières décennies et quelles ont été ses effets sur la situation socio politique, économique et culturel réalisé la différence entre discrets traits culturels qui caractérisent imaginaire collectif des groupes sociaux sont représentés dans des pratiques qui assurent le maintien de groupes sociaux et politiques. Afin de cristalliser le débat quelques approches de l'ethnographie pour démontrer les défis auxquels sont confrontés les sociétés contre la discrimination et de l'ethnocentrisme dans le but de parvenir à la cohésion sociale.

Mots-clés: ethniques, groupes ethniques, l'ethnographie, les groupes sociaux, la cohésion sociale, la discrimination

Recibido: abril 7 de 2011; Aprobado: mayo 17 de 2011 

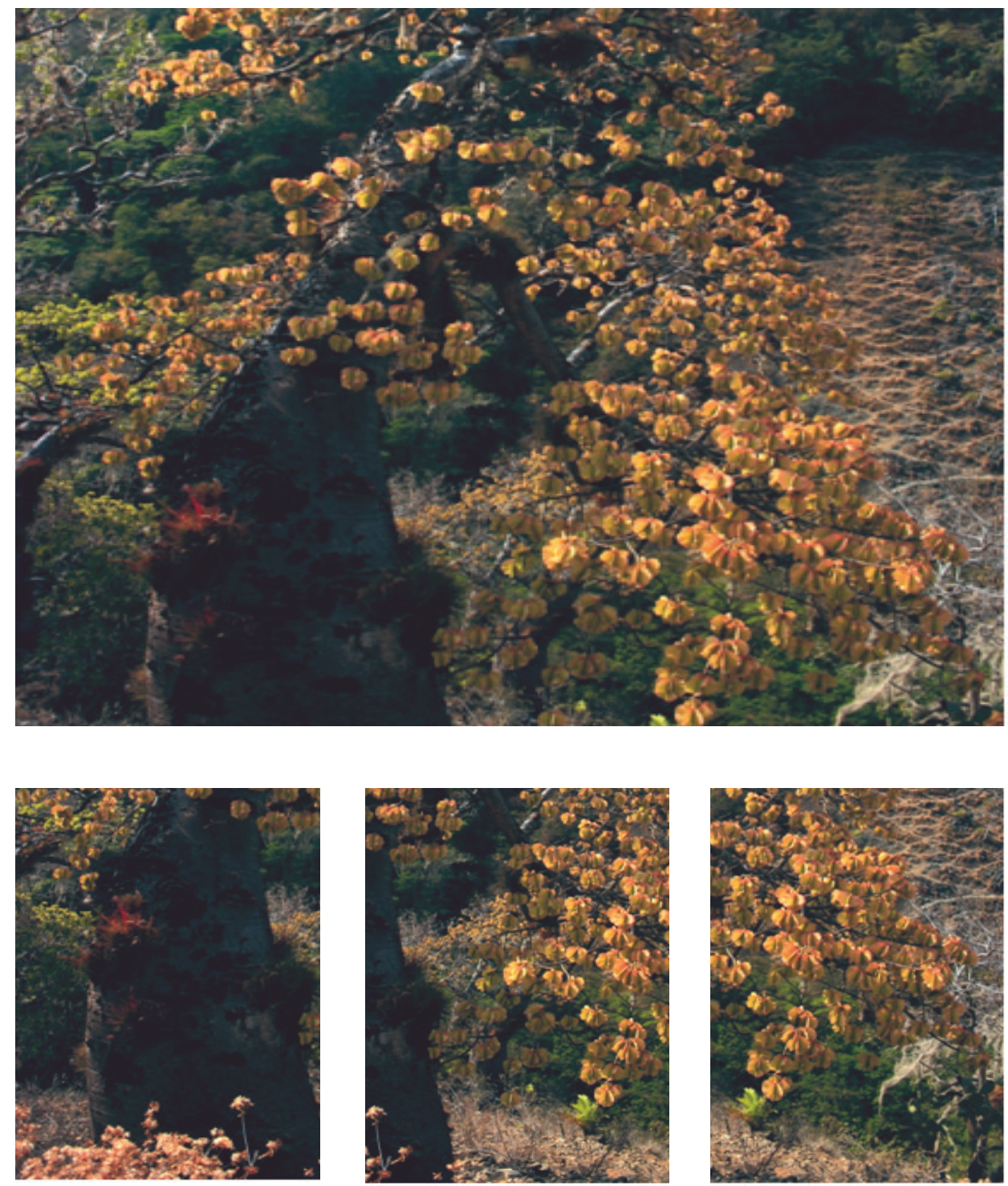

Cañón del Chicamocha - Ceibas Barrigonas

Jorge William Sánchez Latorre 


\section{LOS CLAROSCUROS DE LA ETNICIDAD. EL CULTURALISMO EVALUADO DESDE LA ÓPTICA DE LA COHESIÓN SOCIAL Y LA CIUDADANÍA*}

Joan J. Pujadas

Podría parecer paradójico, por anticuado, un debate a estas alturas del desarrollo de la teoría antropológica sobre el papel analítico que la categoría etnia o grupo étnico pueda tener, tanto en la descripción etnográfica como en la comprensión e interpretación de la diversidad cultural. Un indicio de la incomodidad que suscitan estos términos entre los profesionales de la antropología es la clara tendencia a evitarlos y a sustituirlos por otros términos presuntamente más neutros, como pueblo, tribu, nación o minoría, según los casos y los contextos de uso.

En cualquier caso la etnicidad, como término vinculado a las expresiones de identidad colectiva y del sentimiento de pertenencia a un grupo, es aún uno de los grandes marbetes clasificatorios y un eje temático vigoroso en el ámbito de los estudios sobre diversidad cultural, movilizaciones políticas y estratificación social.

Tomados en cuenta estos dos elementos, el objetivo de este texto es trazar una breve panorámica de la génesis de las categorías etnia y grupo étnico en el ámbito amplio de las ciencias sociales, para parar con más precisión en los principales debates de los últimos 40 años sobre la etnicidad y sus implicaciones culturales, sociales y económicas. Para este propósito, además de explorar las principales aportaciones teóricas de los profesionales de la antropología internacional, se realizará algunas aportaciones etnográficas, a modo de ejemplo, con la intención de clarificar el debate.

\footnotetext{
* El artículo reflexiona sobre el culturalismo revisado desde la óptica de la cohesión social y la ciudadanía, la investigación elaborada por el autor presenta un balance historiográfico del debate étnico a partir del discurso del género para que finalmente cristalizar desde la etnografía los retos sociales frente a la disminución y etnocentrismo en pro de la cohesión social.
} 


\title{
ESENCIALISMO CULTURALISTA EN LA CONCEPCIÓN DE ETNIA O GRUPO ÉTNICO
}

Como destaca Roland Breton (1983: 9 y ss.), la introducción del término etnia se produce en Francia a finales del siglo XIX, aunque no es hasta después de la Segunda Guerra Mundial cuando su uso se generaliza, tanto en Europa como en América. En los medios académicos franceses costó mucho su aceptación, ya que los autores que primero pusieron en boga este término se alineaban en

\begin{abstract}
"tendencias claramente racistas: viejos ideólogos reaccionarios como Vacher de Lapouge, o apóstoles de la 'Europa Nueva' como C. Montandon (director de "L'Ethnie française, revista de doctrina etno-racial y de divulgación científica", publicada en París a partir de marzo de 1941) y J. Boulenger (autor de Le sang français, Denöel, París, 1943)" (Bretón, 1983: 10).
\end{abstract}

La reticencia académica hacia el término, no solamente provenía de una actitud anti-racista, sino de un rechazo hacia todo lo que supusiese enaltecimiento de los hechos étnicos, entendidos como defensa de regionalismos o de apoyo a los hechos diferenciales. La tradición jacobina y centralista del republicanismo francés ubicaba el nacionalismo y su correspondiente identidad nacional en el ámbito del universalismo, del progreso y del predominio de la razón. Elevar la cultura francesa al rango de civilización universal era una operación perfectamente Compatible y justificativa de las políticas culturales asimilacionistas practicadas, tanto en el ámbito de los restos del Imperio colonial francés como, sobre todo, en las regiones del interior de Francia.

La consagración del término proviene de tierras francófonas, fuera del Estado francés, de Bélgica y de Québec, donde la cuestión étnica ocupaba un lugar central en las preocupaciones culturales y políticas en los medios académicos. Uno de los textos más difundidos en la década de los años 1960 fue el de Charles Becquet, L'Ethnie française d'Europe, en el que se sitúa la cuestión valona en el marco de la unidad cultural, lingüística y étnica, que se deriva de un período histórico de longue durée, que arranca de la romanización de la Galia. El esfuerzo de Becquet consiste en insistir en la continuidad nacionalitaria, basada en la existencia de la etnia francesa, por encima de las discontinuidades que supone la consolidación estatal de Francia y Bélgica, que supone la fragmentación de la unidad. ${ }^{1}$

"Los ciudadanos de hoy en día reciben una enseñanza basada solamente en el aspecto político de los sucesos históricos. Todo lo que queda fuera del exágono es "extranjero". ¡Los balones deben hablar "belga", ya que pertenecen a Bélgica! Y todo francés tan sólo tiene responsabilidad etnológica en el interior de Francia. No hay espacio más que para el Estado, entidad impersonal, con objetivos cambiantes, vagando según los caprichos del sistema político del momento (...). Tenemos la obligación de recuperar una noción más sana de las cosas: debemos volver a distinguir lo que es permanente desde la paz romana - a etnia francesa- de aquello que, en todo momento, varía en forma y en extensión - el Estado francés.” (Bécquet, 1963: 164-165). 
Otro texto central en esta literatura francófona es el de Guy Héraud, todavía hoy citado abundantemente: L'Europe des ethnies, aparecido en 1963. El autor traza una completa panorámica de la dominación étnica en el interior de los Estados Nación europeos. La tesis central del libro se centra en el desarrollo de una teoría de la alienación, que se analiza en los planos político, demográfico, cultural, lingüístico, económico, social y psicológico. Introduce el concepto de minoría, que es el resultado histórico del proceso de dominación, en el marco de la construcción del Estado, de una o más etnias por parte de la etnia dominante. Finalmente, propugna el derecho de autodeterminación de las etnias de Europa, en base a un reordenamiento del derecho internacional, que ha de ser el objetivo del federalismo étnico que se propone en la obra. ${ }^{2}$

Por lo que respecta a la tradición anglosajona, también podemos situar a mediados del siglo XX, en plena posguerra europea, la aparición del término grupo étnico, ${ }^{3}$ en sustitución de otros mucho más antiguos en el repertorio clasificatorio de la antropología, como tribu o raza (este último en su acepción británica). Tal vez, el primer texto de posguerra en utilizar esta nueva categoría sea el de Embree y Thomas, Ethnic groups of northern South-east Asia. ${ }^{4}$

Paralelamente en Estados Unidos, unos años más tarde, se pondrán en marcha algunos grandes proyectos de etnografía comparativa, que insistirán en la descripción de los grupos étnicos, entendidos como unidades socio-culturales e identitarias discretas, susceptibles de comparación y contraste. Como señalan Glazer y Moynihan (1975), fue el sociólogo norteamericano David Reisman quien introdujo el término etnicidad hacia 1950. Paralelamente, W. Warner, coordinador del proyecto Yankee City, introduce también dicho término.

Como señala Gilberto Giménez (2006: 130-131),

"el concepto de etnia y sus derivados encuentran inicialmente una gran acogida entre los antropólogos y logran hacer una carrera fulgurante desde el inicio de los 60 y a todo lo largo de los 70 en las ciencias sociales norteamericanas".

Para Giménez, la aceptación generalizada de término

"es concomitante con la aparición de un tipo aparentemente nuevo de conflictos y reivindicaciones llamados "étnicos" que surgen de manera simultánea en las sociedades industrializadas y en las del tercer mundo".

2 Héraud era en los años 60 presidente del Partido Federalista Europeo de Francia y, por tanto, activista de lo que con el tiempo se constituyó como el movimiento de la Europa de los Pueblos.

3 A diferencia de otras lenguas, el inglés no posee el substantivo ethny, un neologismo introducido tan sólo a finales de os años 80. El término equivalente, y sinónimo, de etnia es ethnic group.

4 Hay que hacer notar el carácter adjetivo que el término posee en inglés: étnico proviene del griego étnicos, adjetivo de etnos. Tan sólo muy recientemente ha aparecido en la literatura anglófona el neologismo ethny, si bien hay que señalar que su uso es muy minoritario. Una de las grandes fuentes de consulta en esta materia, el Dictionary of Race and Ethnic Relations, de Ellis Cashmore, cuya primera edición data de 1984, no lo recoge todavía. 
El impulso de los estudios sobre etnicidad tiene un referente importante en la revista Ethnicity, creada en la Universidad de Chicago en 1974, donde publican, entre otros, autores como Brass, Isajiw y Van den Berghe, que promueven el estudio de la etnicidad con una perspectiva comparativa, a partir de la delimitación de grandes áreas culturales. Isajiw (1974), por ejemplo, parte de la identificación empírica de tres focos de etnicidad: Europa, Estados Unidos y lo que él denomina "experiencias tribales". Para el autor estos tres focos corresponden a tres maneras diferentes de expresión de la etnicidad: nacionalidad, subcultura y unidades culturales discretas, respectivamente. Este trabajo de Isajiw se centra en la identificación empírica de los atributos que definen en cada caso la etnicidad, con especial atención al caso estadounidense.

El comparativismo en este campo no es ajeno a los grandes proyectos promovidos, ya con anterioridad, por antropólogos como George Murdock, como el Human Relations Area Files, cuya finalidad era la clasificación de una ingente cantidad de "datos" sobre diferentes tipos de sociedades, con el objeto de identificar las semejanzas y las diferencias entre las culturas y establecer generalizaciones fundadas en las correlaciones entre diferentes rasgos de organización social. Este modelo de investigación es replicado por un sin número de amplios proyectos del tipo Cross-Cultural Survey. ${ }^{5}$

Con esta perspectiva, Raoul Naroll publicaba en 1964 un importante y debatido artículo titulado On ethnic unit classification. En él repasa la herencia de los antropólogos de la primera mitad del siglo XX (Schapera, Radcliffe-Brown, EvansPritchard, Fortes, Murdock, Nadel y Leach ${ }^{6}$, entre otros) en relación al problema del establecimiento de las unidades sociales portadoras de cultura (culture-bearing units). De esta revisión concluye que existen, como mínimo seis posibles criterios para la definición de unidades sociales: (1) la lengua (a la que casi todos otorgan un papel central), (2) la organización política, (3) la contigüidad territorial, (4) la distribución de los rasgos particulares en estudio, (5) el ajuste ecológico, y (6) la estructura de la comunidad local. El propio Naroll acepta que existen problemas con esta lista de criterios, ya que existen muchos casos en que las fronteras de cada uno de estos "indicadores" no coinciden con la de otro u otros criterios. Su propuesta consiste en tomar solamente los tres primeros criterios, ahora mencionados, que

5 Aún cuando esta etapa de posguerra constituye el momento de mayor eclosión de los grandes estudios comparativistas, no olvidemos que una de las magna opera de la etnología americana es la ingente obra, todavía en curso del Handbook of American Indians, ideada y fundada por Franz Boas a inicios del siglo XX.

6 Significativamente, Naroll revisa la obra central de Leach (1954) sobre la estructura social de los kachin de la Alta Birmania, pero no se hace eco del importante artículo de Leach (1960), en que revisa el concepto de frontera en Birmania entre los grupos étnicos donde relativiza la posibilidad de establecer correspondencias entre fronteras territoriales y diacríticos culturales. 
constituyen lo que el denominó cultunits. ${ }^{7}$

Un año más tarde, en 1965, Michael Moerman publica en American Anthropologist un artículo sobre el grupo Lue de Tailandia, preguntándose sobre el significado de la identidad étnica en el marco complejo de articulación de los grupos étnicos o tribales con el Estado. ¿Cómo delimitar las fronteras de un grupo si no es posible establecer discontinuidades culturales claras? En el caso del grupo Lue, existe una coincidencia entre la etiqueta gentilicia como categoría auto-adscriptiva y la etiqueta que marca al grupo lingüístico. Sin embargo, esto no supone que existan diferencias culturales substanciales respecto a grupos vecinos. Para el autor se hace necesario analizar, dada la naturaleza dinámica de la etnicidad, los cambios que se registran en la identidad y en el uso de las etiquetas étnicas entre los miembros y los no miembros del grupo étnico estudiado, así como un análisis etno-semántico que permita una verdadera comprensión de las categorías y las etiquetas étnicas.

En respuesta a Naroll, Moerman afirma que los criterios para delimitar las unidades portadoras de cultura poseen tres deficiencias esenciales:

“(1) En la medida en que lengua, cultura, organización política, etc., no se correlacionan completamente, las unidades delimitadas siguiendo un criterio no coincidirán con las unidades delimitadas con otro.

(2) Si por "cultura" queremos significar un patrón, un conjunto de planes, un proyecto de vida, entonces las unidades delimitadas por una combinación de estos criterios, incluyendo la combinación que Naroll indica, son sólo ocasional e incidentalmente unidades portadoras de cultura.

(3) A menudo resulta difícil discernir discontinuidades de lengua, cultura, política, sociedad o economía con suficiente claridad como para poder establecer fronteras". (Moerman, 1965: 1215) ${ }^{8}$.

Como podemos comprobar, el problema que no consigue resolver el enfoque culturalista de los estudios étnicos es el de hacer coincidir las fronteras que delimitan a un grupo humano con las de un número más o menos grande de rasgos culturales, que marquen el contraste o la discontinuidad cultural con los grupos vecinos. En la práctica lo que sucede es que existen grados importantes de afinidad cultural entre sociedades vecinas, por muy contrastada que sea su diferenciación social. Si la frontera entre un grupo humano y sus vecinos suele estar bien delimitada y puede llegar a corresponder con una línea imaginaria, no sucede lo mismo con la lengua u

7 En el mismo trabajo propone, asimismo, el término cultunit como el concepto que da cuerpo a la unidad básica portadora de cultura. Esta propuesta constituye, según él, una respuesta a la necesidad de operar con unidades comparables en los estudios transculturales y también a la necesidad de una definición rigurosa de éstas si estos estudios quieren ser validados estadísticamente. Una cultunit se define como un grupo de personas que son hablantes vernáculo de dialectos mutuamente inteligibles y que pertenecen también al mismo estado o grupo de contacto contiguo.

8 Naroll (1968) contestó a Moerman ratificándose en la necesidad de usar los grupos étnicos como unidades discretas para hacer posible una comparación a escala mundial. 
otros rasgos culturales que, más que líneas de frontera, tienden a constituir franjas más o menos anchas, donde son observables formas culturales híbridas, que son resultado de largos procesos de interacción.

Por lo que respecta a las fronteras de lenguas y dialectos, vale la pena recordar lo que señalaba Penny (2007: 33) en su ensayo sobre la lengua leonesa medieval:

"Varios lingüistas e historiadores han gastado mucha tinta buscando coincidencias entre fronteras políticas o étnicas, por una parte, e isoglosas, por otras. Pero estas búsquedas han sido infructuosas".

Al igual que, como hemos visto, no era posible trazar una frontera clara y unívoca entre grupos étnicos a partir de la correlación de rasgos culturales, lo mismo sucede con las fronteras dialectales. Éste es el posicionamiento del profesor Penny:

"No existe ninguna "frontera" dialectal que conste de más de una sola isoglosa, lo que equivale a decir que no existen fronteras lingüísticas en el norte peninsular, y que se observa una transición ininterrumpida de costa a costa. Esto implica que es inaplicable aquí la noción tradicional de "dialecto", que supone una variedad lingüistica con límites trazables" (Penny, 2007: 32)9.

¿Qué sucedería, si en lugar de primar la búsqueda de rasgos culturales discretos para caracterizar a los grupos humanos dentro de unas fronteras, tomáramos la frontera en sí como la variable independiente y nos dedicáramos a observar el papel cultural que juega el mismo mantenimiento de la frontera, esto es, el conjunto de prácticas que permiten el control de la membresía del grupo, que incluyen la búsqueda de rasgos y emblemas de identificación interna y de diferenciación externa?

\section{LA FRONTERA: DELIMITACIÓN, MANTENIMIENTO Y PROCESOS CULTURALES Y POLÍTICOS}

La diferenciación cultural entre grupos vecinos no es una realidad estática e inamovible, sino un proceso iterativo que surge de la interacción entre los grupos humanos, que han construido subjetivamente su etnicidad por contraste con el resto de grupos con los que interactúa cotidianamente, para reforzar la propia identidad y el sentimiento de pertenencia. Es en este marco de interacción donde cobran relevancia política las diferencias culturales, entendidas como emblemas de diferenciación social. Es en la frontera donde se construyen las discontinuidades que marcan la oposición de pertenencia / exclusión de los sujetos, adscritos a la membresía de uno

9 Una isoglosa es una línea imaginaria que separa dos áreas geográficas que se distinguen por un rasgo dialectal concreto, sea éste de tipo fonológico, léxico o de otro tipo. Cuando varias isoglosas tienen un recorrido cercano se habla de "haz de isoglosas". 
u otro grupo en contraste.

Esta es la nueva lógica de los estudios de etnicidad que surge a partir, entre otros, del trabajo seminal de Fredrik Barth (1969), en la selección de ensayos y, esencialmente, en la famosa introducción de Los grupos étnicos y sus fronteras, que marca un hito esencial en este campo de estudio.

Para Barth los grupos étnicos no constituyen unidades preconstituidas e inamovibles, susceptibles de ser clasificadas a partir de un catálogo de rasgos culturales observables, sino entidades surgidas de procesos de diferenciación cultural, socialmente establecidos y subjetivamente percibidos, entre grupos que interactúan en marcos interétnicos específicos (Anderson, 2007). Estos marcos de interacción establecen dinámicas de complementariedad, de competencia, de dominación 0 , incluso, de inclusión entre grupos, según sea el marco político y estratégico que las defina. ${ }^{10}$

$\mathrm{Si}$ las diferencias culturales no constituyen la variable independiente en los procesos de interacción entre distintos grupos étnicos: ¿Cuál es el rol de las diferencias culturales entre éstos?

\begin{abstract}
"Analíticamente, los contenidos culturales de las dicotomías étnicas parecen ser de dos órdenes: 1) señales o signos manifiestos: los rasgos diacríticos que los individuos esperan descubrir y exhiben para indicar identidad y que son, por lo general, el vestido, el lenguaje, la forma de vivienda o un general modo de vida, y 2) las orientaciones de valores básicos: las normas de moralidad y excelencia por las que se juzga la actuación. Como pertenecer a una categoría étnica implica ser cierta clase de persona, con determinada identidad básica, esto también implica el derecho de juzgar y ser juzgado de acuerdo con normas pertinentes para tal identidad. Pero ninguna de estas clases de «contenidos culturales» se infiere de una lista descriptiva de los rasgos o diferencias culturales; ni a partir de principios básicos se puede predecir cuáles rasgos serán subrayados y considerados importantes para la organización. En otras
\end{abstract}

10 Si la etnografía clásica había enfatizado el estudio de pequeñas comunidades, haciendo abstracción de los marcos políticos situacionales en que se ubicaban estas sociedades de pequeña escala, las investigaciones de las últimas décadas han abordado el análisis de los procesos étnicos en contextos inclusivos (Brass, 1976; Niemonen, 1999; Van der Berghe, 1976). Así, en América, por ejemplo, el análisis de la etnicidad toma en cuenta las prácticas de los pueblos indígenas en el marco del Estado que, con muy pocas excepciones, lleva a cabo políticas de exclusión social y, al mismo tiempo, de asimilación cultural. En los estudios africanos, por otro lado, existen numerosos estudios que analizan las estrategias de los diferentes grupos tribales por tomar ventaja en el acceso al poder del Estado, en el marco de los procesos de construcción nacional (national-building). Es en los últimos dos decenios, con el incremento exponencial de las diásporas migratorias, cuando el foco principal de atención de los estudiosos se ha desplazado al análisis de inserción social y de diferenciación simbólica de las minorías étnicas en relación a las sociedades receptoras. Aunque de forma minoritaria, también existe una producción significativa sobre las dinámicas políticas y culturales de las minorías nacionales en los estados occidentales plurinacionales (Bartolomé, 2002; Clavero, 2002; Pujadas, 1998, 2000, 2005, 2006, 2008a, 2008b). 
palabras, las categorías étnicas ofrecen un recipiente organizacional capaz de recibir diversas proporciones y formas de contenido en los diferentes sistemas socioculturales." (Barth, 1976: 16).

Las diferencias culturales no evolucionan de manera autónoma, ni es tampoco autónomo el valor o significado diacrítico que poseen como elementos identificadores de un grupo. Cada etapa histórica particular en la relación entre grupos fronterizos activa o subraya determinados elementos, extraídos del propio acerbo cultural, como los marcadores principales del contraste respecto al (a los) grupo (-s) situados al otro lado de la frontera:

"cuando se traza la historia de un grupo étnico en el curso del tiempo, no
se está trazando, simultáneamente y en el mismo sentido, la historia de una
«cultura»; los elementos de la cultura actual de ese grupo étnico no han
surgido del conjunto particular de elementos constitutivos de la cultura del
grupo en el pasado, ya que el grupo tiene una existencia continua organizada
dentro de ciertos límites (normas para establecer pertenencia) que, a pesar de
las modificaciones, la señalan como una unidad continua". (Barth, 1976: 41).

Las diferencias culturales constituyen, pues, construcciones sociales. No hablaremos ni de artificialidad ni de invención de la tradición, término este último bastante denostado. Se trata, simplemente, de destacar el valor subordinado de las diferencias en sí como elementos estructuradores de la interacción social. La diferenciación étnica es, por un lado, procesual, cambiante y adaptativa y, correlativamente, los emblemas culturales de tal diferenciación se ajustan a contextos estratégicos de selección de los emblemas diacríticos que marcan la pertenencia a un grupo y la diferenciación respecto a los demás. Por ello,

"unos rasgos culturales son utilizados por los actores como señales y emblemas de diferencia, otros son pasados por alto y, en algunas relaciones, (incluso) diferencias raciales son desdeñadas y negadas" (Barth, 1976: 6).

Una ilustración etnográfica sobre la evolución del significado social de la frontera nos lo proporciona una investigación reciente realizada en el Pirineo catalán (Pujadas et al., 2007) ${ }^{11}$. Si tomamos dos cortes cronológicos en la vida cotidiana de Cerdaña ${ }^{12}$ (finales del siglo XIX y la actualidad) podremos comprobar cómo la identidad y el

11 En conexión directa con esta investigación en el Pirineo de habla catalana y, principalmente, en relación con el Principado de Andorra, hay que señalar otros trabajos anteriores: Pujadas (1999, 2001a, 2001b, 2003 y 2008b), Comas d'Argemir y Pujadas (1997, 1999), Pujadas et al. (1999).

12 Cerdaña constituye una antigua comarca natural, perteneciente a la Corona de Aragón, que en 1659 fue dividida en dos partes (Alta y Baja Cerdaña) por el Tratado de los Pirineos (1659). La Alta Cerdaña pertenece administrativamente al Departamento francés de los Pirineos Orientales (Región de Lenguadoc-Rosellón), mientras que la Baja Cerdaña constituye una comarca de Cataluña, dividida entre las provincias de Girona y Lleida. 
sentimiento de pertenencia, así como los signos culturales diacríticos que refuerzan el significado "nacional" de la frontera franco-española se han transformado de manera muy severa.

Como señalaba Peter Sahlins (1993), Cerdaña constituye un magnífico observatorio local para testimoniar la aparición y el empoderamiento de los Estados francés y español. Hasta mitad del siglo XIX Cerdaña era una especie de no man's land para los respectivos Estados Nación. En dicho territorio no existían escuelas públicas, ni ferrocarril que las uniese con los respectivos territorios nacionales. La presencia del Estado solamente se substanciaba mediante los dispositivos de guardia y custodia de frontera, pero los carabineros y gendarmes solían ser nativos de la zona y solían interpretar de manera muy laxa su cometido de control fronterizo, especialmente por lo que respecta a las actividades de contrabando. La actividad agropecuaria constituía el eje alrededor del cual se organizaban no solamente las relaciones económicas, sino la vida social, política y cultural. La identidad adscriptiva más marcada era "ser cerdà"13 .

¿Cuál es el significado de esta afirmación? En primer lugar, el conjunto de Cerdaña constituía un único mercado de trabajo. Los contratos de arrendamiento de fincas se realizaban indistintamente entre ciudadanos de un lado y otro de la frontera. La contratación de "mossos"14 era también conjunta ${ }^{15}$. El trasiego diario de la frontera era un indicador de que ésta había sido neutralizada o apropiada por el sistema local. La frontera, más que un elemento de separación, ha constituido siempre un recurso para la población ceretana ${ }^{16}$.

Antes de finales del siglo XIX se alcanza la plena universalización de la escuela en Francia y en la década de los años 1920 se logra en España. La llegada del ferrocarril hasta territorio ceretano, por un lado y otro, se consigue a inicios del siglo XX. Estos dos elementos, junto a otros, constituyen el inicio del proceso de nacionalización de Cerdaña o, dicho de manera más precisa, tendríamos que hablar del proceso de binacionalización. El impacto de la escuela en la vertiente francesa

13 "Ser ceretano". Esta identidad adscriptiva era transfronteriza y compartida, por igual, por los vecinos de uno y otro lado de la frontera.

14 Literalmente, "mozos", jornaleros agrícolas.

15 Toda la gente del país tiene muy presente la forma de contratación, que se realizaba en la plaza de la estación de Puigcerdà, a donde acudían tanto los propietarios necesitados de mano de obra como los jornaleros, dispuestos a ser contratados. Todavía hoy en día viejos campesinos jubilados (algunos de ellos procedentes de Alta Cerdaña) acuden a los bares de la plaza para encontrarse entre ellos y charlar sobre "los viejos tiempos".

16 La frontera constituye un recurso en muchos sentidos. En sentido económico, a través del contrabando, pero también mediante el aprovechamiento del diferencial de precios y salarios o, mediante el diferencial del precio de la vivienda. Constituye también un recurso social y político. Los matrimonios mixtos, muy abundantes todavía hoy en día garantizaban derechos ciudadanos por parte de ambos estados. Pero cruzar la frontera constituía también un recurso de seguridad en épocas de guerra, ya que el acogimiento de los parientes "del otro lado" ponía a salvo a la gente de las contingencias bélicas. 
es mucho más acusado que en la Baja Cerdaña ${ }^{17}$. También lo fueron las políticas de homogeneización cultural, en una época en que se vinculaba la sólida expansión colonial francesa al prestigio de la civilización francófona. A pesar de todo, hasta mediados del siglo XX, el sistema, llamémosle "tradicional" para abreviar, siguió resistiendo y la identidad primordial de los ceretanos, como miembros de una sociedad campesina transnacional, retuvo el statu quo, a pesar del avance material, simbólico y político de ambos Estados.

El largo período, que empieza en julio de 1936, con el inicio de la Guerra Civil española, y que se extiende durante la Segunda Guerra Mundial, no acaba hasta inicios de 1951. Durante 15 años la frontera franco-española se mantiene cerrada y, durante este tiempo, suceden muchas cosas, que van a alterar las premisas en las que se sustentaba esta formación social campesina y sienta las bases de su irreproductibilidad. Dicho de manera escueta, en la Alta Cerdaña, tras la guerra, desaparece de manera mayoritaria la generación de reposición de las unidades domésticas campesinas. Tras tres generaciones de escolarización, la Francia victoriosa, apoyada por el Plan Marshall, abre todo un abanico de posibilidades a los jóvenes ceretanos que, poco a poco, se desentienden del sector primario y abrazan otro tipo de actividades profesionales, desvinculándose además muchos de ellos del territorio. Al mismo tiempo, el Estado francés introduce dos actividades en los pueblos ceretanos, que suponen la llegada de amplios contingentes de población, procedentes de todos los rincones de la geografía francesa. Por un lado, crea numerosos hospitales y casas de reposo, para enfermos crónicos, debido a la bondad del clima. Por otro, se empiezan a desarrollar los deportes de invierno, que son también movilizadores de público y de puestos de trabajo del sector terciario.

Tras la reapertura de la frontera, se constata que un abismo parece separar la Alta de la Baja Cerdaña, pujanza económica frente a pobreza y depresión, democracia y modernización frente a dictadura y tradicionalismo, terciarización frente a actividades agropecuarias. Junto a estos elementos, el dato crucial para entender las suspicacias y el abandono del sentimiento comunitario ceretano, es la presencia muy significativa de "franceses" al norte de la frontera ${ }^{18}$, una gente recién llegada, desconocedora de los antecedentes y de los fuertes vínculos que ataban a las poblaciones y a las personas a través de la frontera. Los franceses ven, mirando al sur, españoles, pobres, atrasados y sometidos a una dictadura oprobiosa. Ninguna complicidad, ningún proyecto compartido. La frontera, entonces, empieza a separar de verdad, a dividir dos proyectos de sociedad, en el marco de dos proyectos políticos "nacionales", que no tienen nada en común. Lo ceretano, entendido como la comunitas transfronteriza

17 Conservamos abundantes relatos de personas mayores, escolarizadas en el período de entreguerras, que recuerdan los castigos que imponían los maestros nacionales franceses a los niños que hablaban catalán en clase. Esta generación ceretana del primer tercio del siglo XX, todavía toda ella catalanoparlante, adoptó de manera muy generalizada la actitud de presionar a sus hijos a que hablaran exclusivamente en francés. Habían internalizado el mensaje diglósico transmitido en las escuelas.

18 Por "franceses" entendemos al conjunto de ciudadanos llegados desde todos los rincones de la República, tras los cambios acaecidos en la economía y en las actividades de la Cerdaña Francesa (o Alta Cerdaña), tras la finalización de la II Guerra Mundial. 
de una sociedad muy débilmente estatalizada, que había retenido instituciones, usos y costumbres de origen medieval ${ }^{19}$, se desarbola y declina frente a la disyuntiva macropolítica de dos Estados que guardan para sí el control de la frontera y que fomentan la diferenciación de sus poblaciones respectivas.

La resignificación de la frontera, pues, no hay que entenderla solamente como un proceso de colonización interna. Se trata también de un cambio significativo de actitud por parte de los agentes locales ceretanos, de un cambio de estrategia cultural. Como campesinos, pese a estar insertos multisecularmente en Estados Nación distintos, los ceretanos (en tanto que campesinos con numerosos intereses compartidos) enfatizaban aquellos elementos culturales diacríticos que los unían, que formaban comunitas. Los ceretanos franceses, interesados en participar de las posibilidades que ofrecía el Estado francés benefactor, optaron por arrinconar, sin eliminar del todo, su identidad primordial, suscribieron nuevos diacríticos que, al mismo tiempo, los acercaban a su nueva condición de franceses de pleno derecho, alejándolos de esa cultura fronteriza compartida transnacionalmente ${ }^{20}$.

\title{
LOS GRUPOS ÉTNICOS COMO UNIDADES POLÍTICAS SIN AUTODETERMINACIÓN
}

\begin{abstract}
"Las ideologías nacionalistas modernas han llevado a cabo diferentes tipos de políticas asimilacionistas para las minorías étnicas y los pueblos subordinados culturalmente distintos, desde la ilusión del crisol estadounidense hasta la integración de los indígenas en las nacionalidades dominantes en América Latina, así como la imposición de un modelo etnocrático de construcción nacional en numerosos estados postcoloniales. La integración nacional,
\end{abstract}

19 La institución del hereu ("heredero universal"), por ejemplo, se mantiene en la Alta Cerdaña hasta tiempos muy recientes, a pesar de que el Código Napoleónico la derogó, junto a la mayoría de elementos del antiguo Código Civil Catalán (Usatges), norma por la que se rigieron siempre todos los ceretanos, desde la Alta Edad Media, y aún después del Tratado de los Pirineos (1659).

20 Hay que señalar, con todo, que en las últimas décadas ha reverdecido de alguna manera ese sentimiento comunitario transnacional. La iniciativa, sin duda, la tiene la sociedad civil y política de la Baja Cerdaña. Aunque en la Cerdaña española, al final, también la terciarización se ha impuesto sobre la actividad agropecuaria, los activistas culturales han intentado acrisolar a favor del catalanismo político el rico caudal simbólico de la llamada cultura tradicional ceretana. Aunque existe una evidente asimetría en cuanto a intencionalidad y proyecto político, no son pocos los ceretanos franceses que se aproximan a esta evocación cultural, atraídos por los logros económicos y políticos alcanzados en los últimos 30 años por los vecinos pobres del sur, pensando que igual no estaba tan mal ser ceretano autónomo en lugar de francés subsidiado y fronterizo. El hecho es que el Departamento de los Pirineos Orientales constituye la zona más pobre de Francia, mientras que Cerdaña es la comarca con mayor nivel de renta en Cataluña. Además, políticamente, la Baja Cerdaña puede desarrollar (aunque sea limitadamente) políticas comarcales propias, dentro de la autonomía que Cataluña tiene como país, frente al férreo centralismo (e inoperancia, según piensan muchos alto-ceretanos) del Estado francés. 
como se entiende en estos casos, requiere que los grupos no dominantes, indígenas y tribales, antiguos esclavos y sirvientes contratados, inmigrantes recientes, minorías territoriales y otros pueblos sin estado propio, renuncien a sus identidades respectivas con el fin de integrarse a una entidad "nacional" más amplia. Aunque esto puede ocurrir espontáneamente en algunos casos, mientras que numerosas etnias por voluntad propia se asimilan a una cultura dominante o mayoritaria, en otros casos las minorías, que en ocasiones son mayorías numéricas, como los pueblos indígenas en algunos países de América Latina, nacionales, étnicas, religiosas o lingüísticas, rechazan esta premisa. Cuando los estados pretenden imponerla se convierte en fuente de enajenación y estímulo para los movimientos disidentes" (Stavenhagen, 2001, $15)^{21}$.

En los últimos treinta años y, a partir en buena medida de la gran herencia legada por el análisis situacionalista en relación a los procesos de etnicidad y al "efecto frontera", las ciencias sociales han dado una vuelta de tuerca muy significativa al enfrentarse al estudio de los grupos étnicos. En los estudios de Barth y sus discípulos los grupos étnicos eran caracterizados como entes sociales relativamente autónomos que interaccionaban con otros grupos de rango similar sin tomar en consideración su articulación con el Estado.

Sin excluir la posibilidad de construir como objeto de estudio la interacción de grupos étnicos y la manera como guardan su frontera o como construyen y reconstruyen su identidad o su sentimiento de pertenencia por contraste a los demás, resulta obvio que todo grupo étnico actúa y se ubica en un marco estatal determinado y que la posición que ocupa en él constituye un elemento fundamental para poder comprender su grado relativo de autonomía o de subordinación. A este respecto, el proceso que acabamos de considerar a propósito de la identidad ceretana en un contexto binacional, resulta aleccionador.

Si incluimos al Estado como actor principal en el análisis de los procesos de etnicidad, nos hallamos ante la necesidad de revisar la categoría grupo étnico como unidad analítica. En el plano político, como en el económico y el cultural, el Estado ejerce su hegemonía frente a los grupos no dominantes:

"indígenas y tribales, antiguos esclavos y sirvientes contratados, inmigrantes recientes, minorías territoriales y otros pueblos sin estado propio" (Stavenhagen, 2001: 15).

Esta gran diversidad de categorías y de situaciones de subordinación es la que se escondía, reificándolo, dentro del término grupo étnico.

Debemos operativizar este listado algo caótico que sugiere Stavenhagen. Para

21 Este ensayo, publicado en forma de artículo, constituye una reelaboración en castellano de la introducción al libro publicado por el mismo autor en inglés unos años antes (Stavenhagen, 1996). 
ello, consideramos que un primer y sólido punto de partida puede ser la distinción que establece el politólogo canadiense Will Kymlicka:
“(...) hay que distinguir entre las minorías nacionales (sociedades diferentes, con Facultades potenciales para autogobernarse, e incorporadas a un mismo Estado) de los grupos étnicos (inmigrantes que han abandonado su comunidad nacional y se han incorporado a otra sociedad)." (Kymlicka, 1999: 32).

Esta distinción se completa, si bien de forma poco sistemática, con una tercera categoría que, a priori, es presentada, también, como minoría nacional, cuando Kymlicka habla del caso de Canadá:

"la evolución histórica del Canadá ha comportado la federación de tres grupos
nacionales diferentes: los ingleses, los franceses y los indígenas" (Kymlicka,
1999: 23-24).

Llama la atención esta manera de categorizar, tanto por la heterogeneidad de los términos que incluye, como por lo que supone de simplificación histórica, ya que los franceses fueron quienes dominaron colonialmente a los pueblos indígenas o naciones originarias y, luego, fueron ellos mismos los colonizados por los ingleses. Mientras los etnónimos francés e inglés remiten a la reproducción americana de dos naciones europeas, hablar de una "minoría nacional indígena" supone aglutinar una heterogeneidad sociocultural máxima en una supuesta categoría unitaria. Esta paradoja es asumida por el mismo Kymlicka, cuando nos aclara lo que debemos entender por indígenas en el caso canadiense:
"El término indígena comprende tres categorías de indígenas (indios, inuits y mestizos) y, al mismo tiempo, el término "indio" es una ficción jurídica, tras el que se esconden numerosas naciones indias diferentes, con sus historias e identidades comunitarias particulares. Los indígenas del Canadá pueden dividirse en once grupos lingüísticos descendientes de diversas sociedades histórica y culturalmente diferentes. Se ha calculado que entre la población indígena existen de treinta y cinco a cincuenta "pueblos" diferentes." (Kymlicka, 1999: 24, nota 2).

En aras de dar cuenta, tanto de las formas de inserción de las diferentes minorías dentro del ámbito del Estado, como del grado de autonomía de que gozan, así como de los horizontes colectivos a los que pueden aspirar estas minorías en relación a la hegemonía del Estado, proponemos una tipología de cuatro categorías: minorías nacionales, minorías étnicas, minorías indígenas y, finalmente, como categoría residual, otras minorías.

Por minorías nacionales, siguiendo al mismo autor, podemos entender: 


\begin{abstract}
“(...) a los grupos etnoculturales que se piensan a sí mismos como naciones dentro de un Estado. Enfrentados al nacionalismo estatal, estos grupos han resistido tradicionalmente la presión a asimilarse a la nación mayoritaria y, en su lugar, se han movilizado para formar su propia comunidad autogobernada, ya sea como Estado independiente o como región autónoma dentro del Estado al que pertenecen”. (Kymlicka y Straehle, 2001: 41).
\end{abstract}

Por minorías étnicas (o grupos étnicos, como los denomina Kymlicka) hemos de entender a aquellos grupos diferenciados de la mayoría social de un Estado por razones culturales, religiosas o raciales. La presencia de estos grupos diferenciados dentro de un Estado se deriva de procesos migratorios. La dinámica que se establece entre estos grupos y el Estado tienen que ver con el conflictivo equilibrio que supone luchar por una igualdad de derechos ciudadanos, al tiempo que se preservan los principales rasgos de su identidad cultural (Pujadas, 1993 y 2001).

Por minorías indígenas nos referimos a aquellos grupos humanos, descendientes de las poblaciones originarias, que fueron colonizados históricamente e incorporados a la fuerza a los territorios coloniales y, posteriormente a los nuevos Estados, surgidos de los procesos de descolonización. Aunque comparten rasgos propios de la minorías nacionales, resulta necesario por motivos analíticos diferenciar esta categoría, ya que las indígenas son minorías nacionales especialmente desfavorecidas, históricamente excluidas, y cuya inserción ciudadana real en el marco del Estado ha resultado ser especialmente problemática, sobre todo por los prejuicios racistas que muestran las mayorías sociales de los Estados, y, también, por la desvalorización y fragmentación de que han sido objeto su tradiciones culturales y prácticas sociopolíticas (Kymlicka, 1996a, 1996b, 2003).

Finalmente, para completar este cuadro clasificatorio, se debe proponer una cuarta categoría, a la que se denomina otras minorías, donde se debe ubicar casos como el del pueblo gitano en Europa o el de la población negra en América, que no son asimilables a ninguna de las tres categorías ya propuestas. En ambos casos se trata de poblaciones de origen exógeno, que se instalan, respectivamente en Europa y América, fruto de su nomadismo o de la deportación esclavista a gran escala. En ambos casos se trata de sociedades asentadas en los respectivos territorios mucho antes de la formación de los Estados Nación contemporáneos, pero cuya inserción ciudadana ha sido especialmente problemática. En el caso gitano, a raíz de sus prácticas nómadas y de su rechazo a la asimilación y en el caso de las poblaciones negras, especialmente en Estados Unidos, a raíz de los prejuicios racistas de la población blanca dominante. La exclusión de la población negra resulta especialmente chocante ya que, a diferencia de la población gitana, más allá de su negritud, no existen rasgos o elementos culturales que los diferencien de las poblaciones blancas ${ }^{22}$.

22 Hay que reconocer este rechazo a la negritud como sintomático y coherente con las políticas homogeneizadoras de los Estados nacionales. Mientras la estrategia para las minorías étnicas, nacionales e indígenas es el asimilacionismo cultural, la estrategia frente a las diferencias raciales es el rechazo y la exclusión, ya que el etnocidio no sirve para cambiar los genes. 
Existen muy pocos ejemplos, si los hay, de Estados nacionales que no estén directamente inmersos en las dinámicas de asimilación forzada o de exclusión de las poblaciones étnica o racialmente diferentes. La pregunta formulada aquí, en términos jurídicos, sería: ¿Cuáles han de ser los límites de las políticas de asimilación o de exclusión por parte de los Estados? ¿Qué nuevos valores y qué nuevas políticas se han de implementar para sustituir las prácticas etnocidas y etnofágicas de los Estados? ${ }^{23}$ En un trabajo reciente, Kymlicka nos aporta su punto de vista:

\begin{abstract}
"Las minorías han sido objeto de numerosas políticas de asimilación y exclusión en pos de la construcción de Estados-nación homogéneos, al tiempo que, históricamente, la comunidad internacional ha hecho caso omiso a estas injusticias. Hoy en día, sin embargo, existe un compromiso creciente con la resolución de este problema, y la idea de que el tratamiento de las minorías es una cuestión que merece una auténtica atención y supervisión internacional goza de un creciente apoyo. Como mínimo, estas normas en evolución establecen límites en los medios que los Estados pueden emplear para lograr sus objetivos de homogeneización nacional. Pero además, al menos implícitamente, ofrecen una visión alternativa del Estado que incorpora la tolerancia como valor nuclear, y de acuerdo con la cual la diversidad constituye una realidad ineludible y tozuda y una característica definitoria del sistema político”. (Kymlicka, 2007:12)
\end{abstract}

Podemos señalar que en los últimos 25 años en países latinoamericanos, por ejemplo: Ecuador, Colombia, Brasil, Panamá o Argentina ha habido significativos cambios legislativos o constitucionales que han proclamado el carácter pluricultural y plurilingüístico del Estado, redefiniendo el rol que los grupos y las culturas indígenas poseen en el marco del Estado-Nación. En otros países federales, como México, ha habido Estados, como Oaxaca, en que se han reinstaurado, aunque de forma parcial, las prácticas del derecho consuetudinario indígena, recuperado cargos, sistemas de gobierno comunitario y mecanismos consuetudinarios de impartición de justicia, se repone con ello, al menos simbólicamente, la dignidad civilizatoria a estos grupos, negada secularmente.

Otra cuestión es si, tal como plantea Barié (2003: 97), existe o no una aplicación práctica de estas reformas legislativas, si la inercia exclusionista y asimilacionista hacia los indígenas, junto a la falta de mecanismos específicos de aplicación de las reformas, no ralentiza o deja sin efecto esta "nueva voluntad" de mutua integración y de acomodación en un contexto identificado, por fin, como multicultural. El

23 El término etnofagia fue usado por Héctor Díaz Polanco en un libro de 1991 sobre las autonomías indígenas. Se trata de una imagen metafórica que sugiere la destrucción del mundo comunitario indígena, "devorando o engullendo al otro". En un texto más reciente (Díaz- Polanco, 2006), señala: "Frente a las acciones brutales del pasado (genocidio, etnocidio), ahora la etnofagia toma cuerpo como un conjunto de "sutiles fuerzas disolventes" del sistema". La hipótesis etnofágica ha sido utilizada por Bretón (2001 y 2008) en su análisis sobre el movimiento indígena del Ecuador y por Patzi (1999) en su análisis sobre la reforma educativa en Bolivia y la violencia simbólica hacia el mundo indígena. 
mismo autor destaca los déficits democráticos que giran en torno a los mencionados procesos, ya que la participación indígena ha sido escasa o inexistente en muchos de estos procesos de cambio legislativo. A doscientos años casi de la descolonización de las repúblicas latinoamericanas la relación entre las élites criollo-mestizas y las minorías indígenas todavía adolece de ese paternalismo con el que el entramado institucional del virreinato del Perú trataba a los indígenas que pretendía proteger, al interpretar sus demandas y suplantar sus voces. Un mecanismo, éste, que Andrés Guerrero $(2000,2010)$ ha apodado como "ventriloquia"24 .

Un indicio de las dificultades por las que atraviesan las administraciones de los países latinoamericanos, en este proceso de transición desde el paradigma asimilacionista al multicultural, se refleja en la imposibilidad de tener un referente estadístico-demográfico mínimamente claro que nos responda a la pregunta simple de: ¿Cuántos son? Según González (1994), citado por Wade (2006, 63-64)

"Se calcula que la población indígena asciende a 34 a 40 millones u 8 a 10\% de la población total en Latinoamérica. Las definiciones de «indígena» varían y de todos modos suelen ser cambiantes y dependen del contexto. Pero se estima que el $90 \%$ de esta población habita en México, Guatemala, Ecuador, Bolivia y Perú. Una serie de estimativos señalan que México tiene 10,5 millones de indígenas ( $12 \%$ de la población), Guatemala tiene 5,4 millones $(60 \%$ del total); Bolivia tiene cerca de 5 millones ( $71 \%$ de la población), mientras que se calcula que en Ecuador del 20 al $40 \%$ de los habitantes son indígenas, y en Perú, del 30 al 45\%” (González, 1994).

En un seminario del CELADE, organizado en Santiago de Chile en octubre de 1998, participaron 60 demógrafos y representantes de los institutos de estadística de 18 países latinoamericanos con la intención de debatir y aunar criterios para afrontar la elaboración de los censos de los años 2000. En esta reunión se evidenció que, junto con los problemas técnicos de administración de los censos (entre ellos la omisión censal en muchas áreas rurales), existía un problema serio para obtener un resultado fiable por lo que respecta a la población indígena. La manera de identificar la condición étnica de los censados en los cuestionarios censales de los diferentes países partía de criterios diferentes, entre ellos: autoadscripción étnica, idioma hablado, pertenencia a comunidad indígena, ubicación geográfica del sujeto censado y otros criterios, entre ellos el vestido o el color de la piel (Peyser y Chakiel, 1999: 355-357).

A pesar de que el volumen de población indígena en la región, censalmente hablado, no ha dejado ce crecer en los últimos 30 años, no existe ninguna duda de que las cifras censales oficiales suponen una sub-representación grave respecto a las estimaciones que diferentes expertos han realizado. Los mismos autores opinan que,

24 Siguiendo la propuesta de Guerrero, Lourdes Tibán analiza en el caso de Cotopaxi la lucha de la población indígena por lograr formas propias de representación y de mediación (Tibán, 2001). 
frente a los 12 millones de indígenas existentes según las fuentes oficiales a inicios de los años 90, la cifra real podría ser tres o cuatro veces superior, si se incluyera en los censos a la población infantil y si se mejoraran los protocolos censales (Peyser y Chakiel, 1994). Claramente ninguno de los criterios de identificación usados es plenamente satisfactorio. El criterio de auto-adscripción (usado en siete de los países) suele dar como resultado una sub-representación, pues los individuos tienden a ocultar su condición étnica en un contexto generalizado de exclusión. Lo mismo sucede con el criterio de la lengua, pues los sujetos se esfuerzan por mostrar su dominio de la lengua oficial. El criterio geográfico resulta solamente aproximativo, pues en "regiones indígenas" habita también población mestiza.

La agrupación en comunidades indígenas parece ser un indicador más objetivo, pero que excluye censalmente a los indígenas que habitan poblaciones predominantemente mestizas o en ciudades (Pereira, 1999).

Posiblemente, como plantea José A. Lloréns, sea una utopía resolver el problema de los censos de poblaciones indígenas, si tomamos en cuenta las dificultades y sesgos contextuales:

“Cómo capturar, mediante un "corte situacional” aplicado de modo universal
al conjunto de la población, toda la dinámica cultural y situacional que se
desenvuelve en continuo cambio según el contexto en que se encuentre
cada grupo étnico? [Por otro lado] teniendo en cuenta la economía de
tiempo y espacio para el levantamiento de información que impone el
propio procedimiento censal, ¿cómo enunciar una pregunta (o a lo más, dos
preguntas) los más eficientemente formulada en términos de obtener la mayor
información con el menor número de palabras, y que sea aplicable a todas y
cada una de las personas que habitan en un país plurilingüe y pluricultural?
En síntesis, ¿cuánta información sobre etnicidad se puede obtener a través de
un censo nacional de población que por acuerdo internacional se debe (y por
razones de economía, sólo se puede) aplicar una vez cada diez años? ¿Qué
valor tiene y qué tanto sirve cualquier información sobre etnicidad obtenida
de este modo? Lloréis" (2002, 675-676)

Estas dificultades censales para establecer un conteo fiable de la población indígena en América Latina constituye un problema en sí mismo y, a la vez, es una metáfora de otro problema mayor: la endeblez y la porosidad de las fronteras de la identidad indígena en el marco del contexto etno-fágico del Estado. Balazote y Radovich lanzaban hace diez años la pregunta de cómo se puede saber si este mapuche es un mapuche y por qué:

"Los dirigentes de la Coordinación de Organizaciones Mapuches (integrada en la Confederación Mapuche Neuquina y el Newén Mapu) han construido una ideología que permite articular un concepto etnicista de la identidad mapuche y de una concepción ecologista: el equilibrio del ecosistema mediante la religión, los saberes ancestrales y la solidaridad social culturalmente integrados y simbólicamente expresados y transmitidos por la lengua 
mapuche: el mapudungun" (Balazote y Radovich, 1999).

Este tipo de discurso se abre paso al desplazar al primordialismo que, presuntamente, constituía la dimensión cohesionadora de la identidad grupal y del sentimiento de pertenencia. La etnicidad, proyectada en la arena nacional, busca argumentos legitimadores y compatibles con una lógica civil y ciudadana. Los mapuches, como minoría indígena dentro de un Estado llamado multicultural, abandonan la lógica comunitaria para buscar la inclusión en la sociedad por medio de una apelación a la "su" tradición que se muestra operativa en términos de una racionalidad ciudadana transversal.

\section{HACIA UN NUEVO PARADIGMA}

No resulta exagerado afirmar que el panorama internacional es sombrío, si nos atenemos a la incapacidad de la mayoría de los estados liberales para gestionar de manera satisfactoria la inclusión de sus minorías en el conjunto de la sociedad civil. Esta incapacidad, si queremos ser ecuánimes, no es achacable solamente al sector político, sino que es compartida por los expertos y asesores que los rodean. MayburyLewis lo plantea en estos términos:

"La etnicidad es un componente inherente a los asuntos humanos que no se desvanecerá ignorándolo. Asimismo, resulta extremadamente difícil de suprimir.

El pánico de los sabios (...) no se debe tanto a su percepción de que la etnicidad domina al mundo - siempre lo ha hecho- sino más bien a que se dieron cuenta de que sus teorías anteriores sobre cómo manejarla resultaron deficientes. Es evidente que se requiere de un nuevo esfuerzo para abordar la etnicidad imaginando sistemas sociales y políticos que le den cabida". (Maybury-Lewis, 1997: 126).

El problema añadido, según mi opinión, es que ese pánico de los sabios del que habla Maybury-Lewis no es, ni mucho menos, generalizado. Desde la confortabilidad de sus despachos hay una mayoría de la clase académica que tiende a banalizar los problemas reales que padece esa mayoría de parias ciudadanos que engrosan las filas de las numerosas minorías construidas por los Estados en un proceso en el que la exclusión simbólica constituye solamente un aspecto, aunque no menor, de su marginación. El etnocentrismo sigue dominando el pensamiento racional de las élites de todo el mundo, incluida la intelectual.

El paternalismo, disfrazado de conciencia multicultural, aún es el único rasgo visible de esas nuevas "políticas correctas" que modifican a regañadientes los parlamentos nacionales para evitar el oprobio de aparecer en las listas negras de movimientos transnacionales como Amnistía Internacional, Human Rights Watch, ACNUR o SOS Racismo, entre otras. 
Se coincide plenamente con Maybury-Lewis en su apelación a la necesidad de una nueva teoría comprensiva de los Estados multiétnicos que revise ese legado del Estado napoleónico que se resume en el concepto de integración, que suplanta las conciencias colectivas, que minimiza el componente civilizatorio del legado de las comunidades étnicas y que infantiliza, exotiza (o, simplemente, excluye de raíz) las voces de sus actores. En Ecuador, Bolivia o México, entre otros muchos países, y a pesar de las enormes dificultades para su génesis y desarrollo, ha emergido con fuerza en los últimos decenios un movimiento indígena, constituido en actor social y político de primera magnitud, que ha mostrado su capacidad para imponer en la agenda política de los Estados su reclamación de equidad ciudadana y del derecho a la especificidad cultural y a una identidad diferenciada.

Uno de los logros de estos nuevos movimientos sociales indígenas ha sido mostrar, contra los prejuicios racistas inherentes en el etnocentrismo de Estado, que su proyecto político no se ancla en el pasado, sino que el actor social indígena dispone de un proyecto de presente y de futuro. Si, como académicos, reclamamos el derecho de las minorías (nacionales, étnicas, indígenas y de cualquier otro tipo) a manifestarse y a participar de manera equitativa en el debate político sobre la conformación de un nuevo Estado multiétnico, como ciudadanos, hemos de desear y promover que la academia sea, asimismo, inclusiva y contenga voces indígenas en la formulación de esa nueva teoría de los Estados multiétnicos que, con MayburyLewis, consideramos imprescindible.

\section{REFERENCIAS}

Anderson, Robert., (2007), «Entrevista con Fredrik Barth », AIBR, v. 2, No. 2, pp. 179-195.

Balazote, Alejandro; Radovich, Juan. C., (1999) "Indigenas y fronteras: los límites de la nacionalidad", en Balazote, A; Radovich, J. C. (Comps.), Estudios antropológicos sobre la cuestión indígena en la Argentina, Buenos Aires, Minerva.

Barié, Cletus G., (2003) Pueblos indigenas y derechos constitucionales, La Paz, Instituto Indigenista Interamericano (México), Comisión Nacional para el desarrollo de los pueblos indígenas (México), Abya Yala (Quito).

Barth, Fredrik., (1976) Los grupos étnicos y sus problemas, México, FCE

Bartolomé, Miguel., (2002) "Movimientos indios en América Latina. Los nuevos procesos de construcción nacionalitaria”, Desacatos, Vol. 10, pp. 148-166.

Becquet, Charles., (1963) L'Ethnie française d'Europe, Paris, Nouvelles Éditions Latines. 
Boulenger, Jacques., (1943) Le sang français, París, Denöel

Brass, Paul R., (1976) "Ethnicity and Nationality Formation", Ethnicity, Vol. 3, pp. 225-241.

Breton, Roland, (1983) Las etnias, Barcelona, Oikos-Tau.

Bretón, Víctor, (2001) “Capital social, etnicidadydesarrollo: algunas consideraciones críticas desde los andes ecuatorianos", Yachaikuna, núm. 2, (ICCI), Quito, 20 pp. En Línea: http://icci.nativeweb.org/yachaikuna/2/breton.pdf.

Bretón, Víctor, (2008) "De la ventriloquia a la etnofagia o la etnitización del desarrollo rural en los Andes ecuatorianos", en Martínez, M., Rodríguez, E. (Comps.), Intelectuales, mediadores y antropólogos. La traducción y la interpretación de lo global en lo local, San Sebastián, Ankulegi, pp. 113-136.

Cashmore, E. Ellis, (1984) Dictionary of Race and Ethnic Relations, Londres, Routledge.

Clavero, Bartolomé, (2002) Multiculturalismo constitucional, con perdón, de veras y en frío, Revista Internacional de Estudios Vascos, vol. 47, num. 1, 35-62.

Comas d'Argemir, Dolors; Pujadas, Joan J., (1997) Andorra, un país de frontera, Barcelona, Ed. Alta Fulla.

Comas d'Argemir, Dolors; Pujadas, Joan J., (1999) "Living in/on the frontier: Migration, identities and citizenship in Andorra", Social Anthropology, Vol. 7, pp. 253-264.

Díaz Polanco, Héctor, (1991) Autonomía regional. La autodeterminación de los pueblos indios. México, Siglo XXI.

DíazPolanco, Héctor,(2006)Elogio dela diversidad. Globalización, multiculturalismo y etnofagia, México, Siglo XXI.

Embree, John ; Thomas, W.L., (1950) Ethnic groups of northern South-east Asia, New Haven, Yale University Press.

Giménez, Gilberto, (2006) "El debate contemporáneo en torno al concepto de etnicidad", Cultura y representaciones sociales, año 1, No. 1, pp. 129-144

Glazer, Nathan; Moynihan, Daniel., (Comps.) (1975) Ethnicity: Theory and Experience, Cambridge, Mass., Harvard University Press.

Guerrero, Andrés, (2000) "El proceso de identificación: sentido común ciudadano, ventriloquia y transescritura", en Guerrero, A. (Comp.), Etnicidades, Quito, Flacso, pp. 9-60.

Guerrero, Andrés, (2010) Administración de poblaciones, ventriloquia $y$ transescritura, Quito, Flacso.

Héraud, Guy, (1974) L'Europe des Ethnies, París, Presses d'Europe, ed. original 1963. Isajiw, Wsevolod, (1974) “Definition of Ethnicity”, Ethnicity, Vol. 1, pp. 111-124.

Kymlicha, Will, (1996a) "Federalismo, nacionalismo y multiculturalismo", Revista Internacional de Filosofía Política, Vol. 7, pp. 20-54 
Kymlicha, Will, (1996b) "Derechos individuales y derechos de grupo en la democracia liberal", Isegoría, No. 14, pp. 5-36.

Kymlicha, Will, (1999), Ciutadania multicultural. Una teoría liberal dels drets de les minories, Barcelona, Ediuoc.

Kymlicha, Will, (2003) La política vernácula. Nacionalismo, multiculturalismo y ciudadanía, Barcelona, Paidós.

Kymlicka, Will, (2007) "La evolución de las normas europeas sobre los derechos de las minorías: los derechos a la cultura, a la participación y la autonomía", Revista Española de Ciencia Política, No. 17, pp. 11-50.

Kymlicha, Will, Straehle, Christine., (2001) Cosmopolitismo, Estado-nación y nacionalismo de las minorías. Un análisis crítico de la literatura reciente, México, UNAM, Instituto de Investigaciones Jurídicas. Traducción de Karla Pérez Portilla y Neus Torbisco. En línea: http://centauro.cmq.edu.mx/dav/libela/ pdfS/legisla/ 080109049.pdf.

Lapierre, Jean-William, (1996) "Préface", en Poutignar, Philippe ; Streiff-Fenart, Jocelyne, Théories de l'ethnicité. París: PUF, pp. 9-14.

Leach, Edmund. (1954) Political Systems of Highland Burma. A Study of Kachin Social Structure, Londres, Berg.

Leach, Edmund, (1960) «The frontiers of Burma », Comparative Studies of Society and History, Vol. 3, pp. 49-68.

Lloréns, José A, (2002) “Etnicidady censos: los conceptos básicos y sus aplicaciones", Boletín del Instituto Francés de Estudios Andinos, vol. 31, núm. 3, pp. 655-680.

Maybury-Lewis, David., (1997) "Vivir con al etnicidad: la necesidad de un nuevo paradigma", en Arizpe, Lourdes (Comp.), Dimensiones culturales del cambio global. Una perspectiva antropológica. México, UNAM, pp. 115-133.

Moerman, Michael, (1965) "Ethnic identity in a complex civilization: who are the Lue?", American Anthropologist, Vol. 67, pp. 1215-1230.

Naroll, Raoul, (1964) «On ethnic unit classificatio », Current Anthrpology, Vol. 5, núm. 4, pp. 283-291.

Naroll, Raoul, (1968) "Who the Lue are?”, en June Helm (Comp.), Essays on the problem of tribe, Proceedings of the 1967 Annual Spring Meeting of the American Ethnological Society, Seattle, University of Washington Press, pp. 72-79.

Niemonen, J, (1999) « Deconstructing Cultural Pluralism », Sociological Spectrum, Vol. 19, núm. 4, pp. 401-419.

Patzi, Félix, (1999) "Etnofagia estatal: nuevas formas de violencia simbólica", Bulletin de l'Institut Français d'Études Andins, vol. 28, núm. 3, pp. 535-559.

Penny, Ralph, (2007) “'Continuum' dialectal y fronteras estatales. El caso del leonés medieval", en Argutorio, vol. 18, pp. 32-37.

Pereira, Luis, (1999) "Criterios de identificación del origen étnico con especial referencia a los pueblos indígenas y originarios”, en CELADE, América Latina: 
aspectos conceptuales de los censos del 2000, Santiago de Chile, CEPAL, pp. 343-352.

Peyser, Alexia; Chakiel, Juan, (1999) "La identificación de poblaciones indígenas en los censos de América Latina", en CELADE, América Latina: aspectos conceptuales de los censos del 2000, Santiago de Chile, CEPAL, pp. 353-363.

Peyser, Alexia; Chakiel, Juan., (1994) "La población indígena en los censos de América Latina", Estudios Sociodemográficos de Pueblos Indígenas, CELADE, CIDOB, FNUAP y ICI, LC/DEM/G. 146, Serie E, No. 40.

Pujadas, Joan J, (1993) Etnicidad, Madrid, Eudeba.

Pujadas, Joan J., (1998) "Mestizaje, cosmopolitismo y otras formas de racismo", en AADD, La interculturalidad que viene, Barcelona, Icaria, pp. 255-267.

Pujadas, Joan J, (2000) "Minorías étnicas y nacionales frente al Estado y la globalización: reflexiones desde el otro lado del Atlántico", en Reina, L. (Comp.), Los retos de la etnicidad en los estados nación del siglo XXI, México, CIESAS-Ed. Porrúa, pp. 101-121.

Pujadas, Joan J., (2001a) "Andorra. El proceso de construcción nacional de un microestado pirenaico", en González Reboredo, X. M. (Comp.): Etnicidade e nacionalismo. Santiago de Compostela, Consello da Cultura Galega, pp. 353373.

Pujadas, Joan J., (2001b) “Frontera, nación y ciudadanía: los usos de la lengua en los confines de Aragón y Catalunya", en Represa, F.; Gómez, I. (Comps.), Lengua, cultura y evolución humana. Oiartzun, Sendoa Eds., pp. 21-40.

Pujadas, Joan J., (2003) “Biografía de una frontera: procesos de globalización en dos enclaves pirenaicos: Andorra y Cerdaña ", en Aguilar, E.; Bueno, C. (Comps.), Las Pujadas, Joan J., (2006) "Diversidad cultural frente a nacionalismo político: los frentes abiertos en el ámbito educativo”, Tiempos de América, No. 13, pp. 121-132.

Pujadas, Joan J., (2008a) "Fronteres, pluralisme i convivència", en Silvio Previtera, Límits i identitat ètnica: una recerca a Fraga (Osca), Lleida, Universitat de Lleida, pp. 9-15.

Pujadas, Joan J., (2008b) “Integración, convivencia y transnacionalismo", en García Roca, J.; Lacomba, J. (Comps), La inmigración en la sociedad española: una radiografía multidisciplinar, Barcelona, Bellaterra, pp. 289-302.

Pujadas, Joan J.; Martín, E.; Pais de Brito, J., (Comps.) (1999) Globalización, fronteras culturales y politicas y ciudadanía, Santiago de Compostela, AGA-FAAEE.

Pujadas, Joan J.; Dietz, Gunther (2005), Etnicidad en Latinoamérica: movimientos sociales, cuestión indígena y diásporas migratorias, Sevilla, AAA-FAAEE.

Pujadas, J.J. ; Soronellas, M. ; Casal, G., (2007) Cada casa és un món. Família, economia $i$ arquitectura a Cerdanya, Barcelona, Departament de Cultura (Generalitat de Catalunya. 
Sahlins, Meter, (1993) Fronteres i identitats: La formació d'Espanya i França a la Cerdanya, segles XVII-XIX, Vic, Ed, Eumo.

Stavenhagen, Rodolfo (1996), Ethnic Conflict and the Nation-Sate, Londres, McMillan.

Stavenhagen, Rodolfo, (2001) "Conflictos étnicos y Estado nacional: conclusiones de un anàlisis comparativo”, Estudios Sociológicos, vol. XIX, No. 55, pp. 3-26.

Tibán, Lourdes., (2001) “La ruptura del ventrilocuismo y el establecimiento de normas propias de representación en el pueblo kichwa de Cotopaxi”, Yachaikuna, núm. 1 En línea: http://icci.nativeweb.org/yachaikuna/1/tiban.pdf.

Van den Berghe, Pierre L., (1976) “Ethnic Pluralism in Industrial Societies. A Special Case?", Ethnicity, Vol. 3, pp. 242-255.

Vázquez, Héctor, (2002) "Procesos identitarios, minorías étnicas y etnicidad: los mapuches de la República Argentina", Amnis, No. 2 En línea: http://amnis. revues.org/167.

Wade, Meter, (2006) "Etnicidad, multiculturalismo y políticas sociales en Latinoamérica”, Tabula Rasa (Bogotá), No. 4, pp. 59-81. 